\title{
Intraspecific morphological and genetic differentiation in Scrophularia grayana (Scrophulariaceae)
}

Takuro Kamada • Tadashi Yamashiro •

Masayuki Maki

Published online: 22 June 2007

(C) The Botanical Society of Japan and Springer 2007

Erratum to: J Plant Res (2007) 120:437-443 DOI 10.1007/s10265-007-0084-1

Part of Fig. 2 was inadvertently cropped during correction by the publisher. The figure is correctly shown here.

The online version of the original article can be found under doi:10.1007/s10265-007-0084-1.

T. Kamada

Biological Institute, Faculty of Science,

Tohoku University, Aoba, Sendai 980-8578, Japan

T. Yamashiro

Department of Life Science,

Faculty of Integrated Arts and Sciences,

The University of Tokushima,

Tokushima 770-8502, Japan
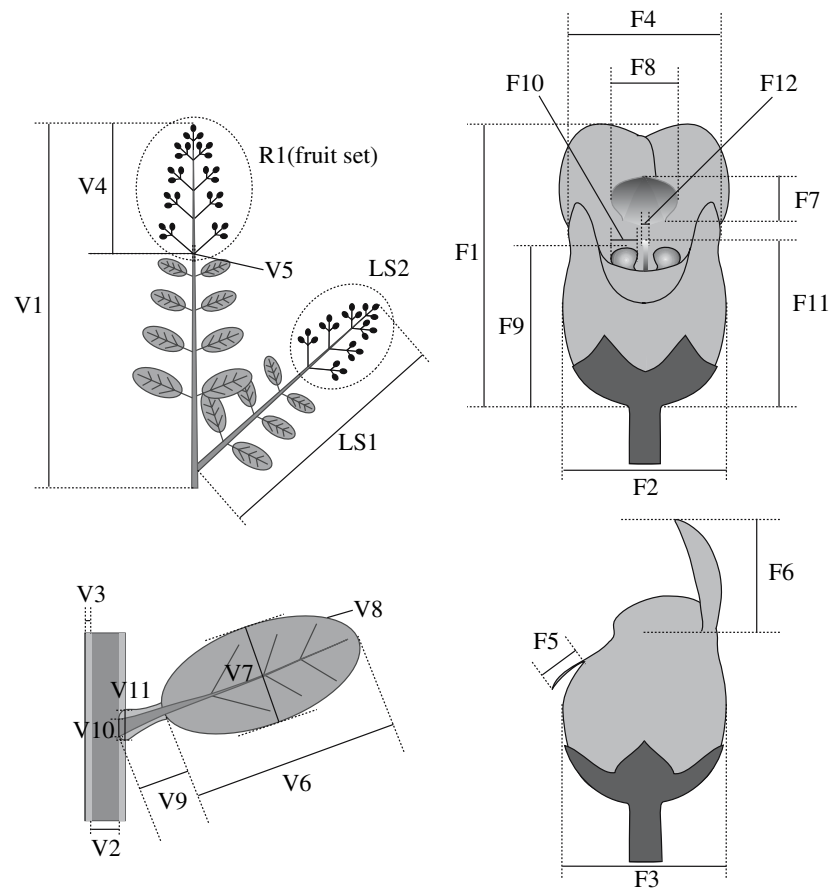

Fig. 2 Definitions of the characteristics measured in morphometric analysis

M. Maki $(\bowtie)$

Division of Ecology and Evolutionary Biology,

Graduate School of Life Sciences, Tohoku University,

Aoba, Sendai 980-8578, Japan

e-mail: maki@mail.tains.tohoku.ac.jp 